\title{
Gambaran Neuritis Optik di RSUP Prof. Dr. R. D. Kandou Manado Tahun 2015-2017
}

\author{
Holy V. A. Kondengis, ${ }^{1}$ Sigmund I. E. Tumewu, ${ }^{2}$ Rillya D. P. Manoppo ${ }^{2}$
}

\author{
${ }^{1}$ Program Studi Pendidikan Dokter Fakultas Kedokteran Universitas Sam Ratulangi Manado \\ ${ }^{2}$ Bagian Ilmu Kesehatan Mata Fakultas Kedokteran Universitas Sam Ratulangi Manado \\ Email: hollykds@gmail.com
}

\begin{abstract}
Optic neuritis is a condition where inflammation occurs in the optic nerve. This disease is accompanied by sudden vision decrease that can be temporary or even permanent if not treated well. This study was aimed to obtain the profile of optic neuritis at Prof Dr. R. D. Kandou Hospital Manado from year 2015 to 2017. This was a retrospective and descriptive study using patients' medical records from year 2015 to 2017. There were 24 optic neuritis patients involved in this study; males were predominant as many as 13 patients (54\%). Optic neuritis were more common at age interval of 26-45 years as many as 11 patients (46\%). Based on occupation, housewifery had the highest percentage (25\%). Most cases of optic neuritis could not be classified in this study as many as 14 patients (58\%). In conclusion, optic neuritis was more common in males, age interval 26-45 years. Based on its type, most optic neuritis cases could not be classified.
\end{abstract}

Keywords: optic neuritis

\begin{abstract}
Abstrak: Neuritis optik merupakan kondisi dimana terjadi inflamasi pada saraf optik. Penyakit ini disertai dengan penurunan penglihatan secara tiba-tiba yang dapat bersifat sementara atau bahkan sampai permanen jika tidak ditangani dengan baik. Penelitian ini bertujuan untuk mengetahui gambaran neuritis optik di RSUP Prof. Dr. R. D. Kandou Manado tahun 2015-2017. Jenis penelitian ialah deskriptif retrospektif dengan menggunakan data rekam medik pada tahun 2015 - 2017. Hasil penelitian menunjukkan terdapat 24 pasien neuritis optik pada tahun 2015-2017 di RSUP Prof. Dr. R. D. Kandou Manado. Berdasarkan jenis kelamin lebih banyak ditemukan pada laki-laki sebanyak 13 pasien (54\%) sedangkan untuk usia ditemukan pada interval usia 26-45 tahun sebanyak 11 pasien (46\%). Berdaasarkan pekerjaan, neuritis optik terbanyak didapatkan pada ibu rumah tangga (IRT) sebanyak 6 pasien $(25 \%)$. Untuk jenis neuritis optik umumnya didapatkan yang tidak diklasifikasi jenisnya sebanyak 14 pasien (58\%). Simpulan penelitian ini ialah neuritis optik lebih banyak didapatkan pada laki-laki, dengan rentang usia 26-45 tahun, jenis neuritis optik yang tidak diklasifikasi, dan lebih didominasi jenis pekerjaan IRT.
\end{abstract}

Kata kunci: neuritis optik

\section{PENDAHULUAN}

Neuritis optik merupakan inflamasi pada saraf optik. ${ }^{1}$ Penyakit ini disertai dengan penurunan penglihatan yang dapat bersifat sementara atau bahkan sampai permanen jika tidak ditangani dengan baik. Salah satu komplikasi yang dapat timbul yaitu keru-sakan saraf optik, ${ }^{2}$ Kasus neuritis optik sering dikaitkan dengan multiple sclerosis atau neuromyelitis optica tetapi bisa juga terjadi secara terpisah. ${ }^{3}$ Dalam kasus yang terkait dengan multiple sclerasis, neuritis optik biasanya merupakan manifestasi dini atau permulaan penyakit. ${ }^{1}$ Studi tindak lanjut jangka panjang menunjukkan bahwa $75 \%$ dari perempuan yang mengalami neuritis optik pada akhirnya mengalami multiple sclerosis. ${ }^{3}$ 
Studi dari Swedia dan Denmark melaporkan angka insiden onset baru neuritis optik berkisar 4-5 kasus per 100.000 orang. Pasien yang tinggal di daerah beriklim sedang cenderung mengalami neuritis optik. Perempuan dua kali lebih sering terkena dibandingkan laki-laki. Kasus neuritis optik tipikal sering terjadi pada dewasa muda sekitar usia 20-45 tahun, sedangkan pada kasus neuritis optik atipikal dapat dilihat pada pasien lanjut usia. ${ }^{3}$ Pada anak, penyakit ini cenderung bersifat bilateral sedangkan pada dewasa cenderung bersifat unilateral. $^{2}$

Inflamasi pada saraf optik diklasifikasi berdasarkan lokasi yaitu papilitis, neuritis retrobulbar, dan neuroretinitis. ${ }^{4}$ Papilitis adalah inflamasi pada diskus optikus ditandai dengan adanya hiperemis dan edema. Neuritis retrobulbar adalah inflamasi saraf optik yang terjadi di belakang bola mata sehingga pada gambaran fundus tidak ditemukan adanya perubahan/ abnormalitas. ${ }^{5}$ Neuroretinitis hampir sama dengan papilitis dan ditandai dengan adanya macular star. ${ }^{4}$

Berdasarkan latar belakang ini maka peneliti tertarik untuk mengetahui gambaran neuritis optik di RSUP Prof. Dr. R. D. Kandou Manado.

\section{METODE PENELITIAN}

Penelitian ini dilakukan di Poliklinik Ilmu Kesehatan Mata dan Instalasi Rekam Medik RSUP Prof. Dr. R. D. Kandou Manado pada bulan September-November 2019 dengan subjek penelitian ialah semua pasien yang berobat di Poliklinik Mata RSUP Prof. Dr. R. D. Kandou Manado pada tahun 2015-2017 yang terdiagnosis neuritis optik. Jenis penelitian ialah deskriptif retrospektif dengan menggunakan data rekam medik.

Data rekam medik dari pasien neuritis optik tahun 2015-2017 di Poliklinik Ilmu Kesehatan Mata diperoleh dari Instalasi Rekam Medik RSUP Prof. Dr. R. D. Kandou kemudian diolah sesuai dengan variabel penelitian (usia, jenis kelamin, pekerjaan, klasifikasi neuritis optik) dan disajikan dalam bentuk tabel dan diagram.

Penelitian ini telah mendapat persetu- juan dari Komisi Etik Penelitian Kesehatan RSUP Prof. Dr. R. D. Kandou Manado, dengan nomor keterangan layak etik yaitu No.053/EC/KEPK-KANDOU/X/2019.

\section{HASIL PENELITIAN}

Penelitian dilakukan secara retrospektif di Poliklinik Ilmu Kesehatan Mata dan Instalasi Rekam Medik RSUP Prof. Dr. R. D. Kandou Manado. Tabel 1 memperlihatkan terdapat 24 pasien yang terdiagnosis neuritis optik selama tahun 20152017 dengan jumlah kasus per tahun hampir sama banyak. Berdasarkan jenis kelamin, jumlah pasien laki-laki sebanyak 13 orang $(54 \%)$ sedangkan perempuan 11 orang $(46 \%)$.

Tabel 1. Jumlah kasus neuritis optik berdasarkan tahun

\begin{tabular}{cc}
\hline Tahun & $\begin{array}{c}\text { Jumlah kasus } \\
\text { neuritis optik }\end{array}$ \\
\hline 2015 & 9 \\
2016 & 7 \\
2017 & 8 \\
Total & 24 \\
\hline
\end{tabular}

Tabel 2 memperlihatkan bahwa berdasarkan kategori usia, didapatkan kasus neuritis optik pada tahun 2015 - 2017 lebih banyak pada rentang usia 26-45 tahun sebanyak 11 orang (46\%), diikuti rentang usia 46-65 tahun sebanyak 7 orang (29\%), dan yang paling sedikit pada usia $<25$ tahun sebanyak 6 orang $(25 \%)$.

Tabel 2. Jumlah kasus neuritis optik berdasarkan kategori usia

\begin{tabular}{ccc}
\hline $\begin{array}{c}\text { Kategori } \\
\text { usia }\end{array}$ & Jumlah & $\begin{array}{c}\text { Persentase } \\
(\%)\end{array}$ \\
\hline$<25$ tahun & 6 & $25 \%$ \\
$26-45$ tahun & 11 & $46 \%$ \\
$46-65$ tahun & 7 & $29 \%$ \\
$>66$ tahun & - & - \\
Total & 24 & $100 \%$ \\
\hline
\end{tabular}

Tabel 3 memperlihatkan bahwa berdasarkan jenis pekerjaan, yang paling banyak ialah ibu rumah tangga (IRT) sebanyak 6 pasien (25\%), diikuti pegawai swasta seba- 
nyak 5 pasien $(21 \%)$ sedangkan yang paling sedikit ialah pekerjaan tukang dan juga dibawah usia sebanyak masing-masing 1 pasien $(4 \%)$.

Tabel 3. Jumlah kasus neuritis optik berdasarkan pekerjaan

\begin{tabular}{ccc}
\hline Jenis pekerjaan & Jumlah & $\begin{array}{c}\text { Persentase } \\
(\%)\end{array}$ \\
\hline IRT & 6 & $25 \%$ \\
Pegawai swasta & 5 & $21 \%$ \\
Pelajar & 2 & $8 \%$ \\
Di bawah umur & 1 & $4 \%$ \\
Mahasiswa & 2 & $8 \%$ \\
Petani & 2 & $8 \%$ \\
Tukang & 1 & $4 \%$ \\
PNS & 3 & $13 \%$ \\
Tidak bekerja & 2 & $8 \%$ \\
Total & 24 & $100 \%$ \\
\hline
\end{tabular}

Tabel 4 memperlihatkan bahwa berdasarkan jenis neuritis optik didapatkan yang paling banyak yaitu neuritis optik yang tidak diklasifikasi jenisnya sebanyak 14 pasien $(58 \%)$, papilitis sebanyak 10 pasien (42\%), sedangkan neuritis retrobulbar dan neuroretinitis tidak ada datanya.

Tabel 4. Jumlah kasus neuritis optik berdasarkan jenis neuritis optik

\begin{tabular}{ccc}
\hline $\begin{array}{c}\text { Jenis } \\
\text { neuritis optik }\end{array}$ & Jumlah & $\begin{array}{c}\text { Persentase } \\
(\%)\end{array}$ \\
\hline Tidak diklasifikasi & 14 & $58 \%$ \\
Papilitis & 10 & $42 \%$ \\
Neuritis & & \\
retrobulbar & - & - \\
Neuroretinitis & - & - \\
Total & 24 & $100 \%$ \\
\hline
\end{tabular}

\section{BAHASAN}

Pada penelitian ini didapatkan 24 pasien yang terdiagnosis neuritis optik tahun 2015, 2016, dan 2017. Jumlah pasien untuk ketiga tahun tersebut hampir sama.

Berdasarkan jenis kelamin pada pasien neuritis optik didapatkan persentase yang lebih tinggi pada laki-laki dibandingkan perempuan (54\% vs $46 \%$ ). Hasil ini tidak sesuai dengan teori yang menyatakan bahwa perempuan lebih sering dibandingkan laki-laki. ${ }^{6}$ Hasil penelitian ini juga tidak selaras dengan penelitian oleh Hidayat $^{6}$ yang melaporkan di RS M. Djamil Padang dari Januari 2016-April 2017 didapatkan 9 pasien terdiri dari 4 orang laki-laki dan 5 orang perempuan. Hal ini kemungkinan dipengaruhi oleh beberapa faktor seperti kebiasaan merokok pada lakilaki ${ }^{7}$ dan juga kemungkinan dipengaruhi oleh kurangnya representatif pada periode penelitian.

Berdasarkan kategori usia, pada penelitian ini didapatkan yang terbanyak ialah rentang usia 26-45 (46\%) diikuti rentang usia 46-65 tahun (29\%), dan paling sedikit pada usia $<25$ tahun $(25 \%)$, namun angka kejadian neuritis optik beragam mulai dari usia 5-65 tahun. Hasil ini masuk dalam kajian teori yaitu puncak insiden terjadi pada rentang usia 15-49 tahun. ${ }^{8}$ Pada penelitian oleh Hidayat ${ }^{2}$ yang dilakukan di Rumah Sakit M. Djamil didapatkan dari 9 kasus yang datang, usia termuda ialah 21 tahun dan yang tertua ialah 45 tahun, dengan rerata 34 tahun.

Berdasarkan jenis pekerjaan, pada penelitian ini didapatkan yang terbanyak ialah IRT (25\%), diikuti dengan pekerjaan pegawai swasta $(21 \%)$, sedangkan yang paling sedikit pada pekerjaan tukang dan juga di bawah umur (masing-masing 4\%). Peneliti berasumsi bahwa kejadian neuritis optik tidak berhubungan dengan pekerjaan dan sampai saat ini belum ada penelitian mengenai hubungan pekerjaan dengan terjadinya neuritis optik.

Berdasarkan jenis neuritis optik didapatkan bahwa dari 24 pasien neuritis optik pada penelitian ini, paling banyak yaitu neuritis optik yang tidak diklasifikasi jenisnya $(58 \%)$ dan untuk papilitis sebanyak 10 pasien (42\%), sedangkan untuk neuritis retrobulbar dan neuroretinitis tidak ada datanya. Hal ini kemungkinan karena pasien datang masih pada stadium awal. Hal ini juga berkaitan dengan teori yang menjelaskan mengenai stadium perubahan pada neuritis optik. Saat pertama kali didiagnosis neuritis optik akut pada pemeriksaan fisik tampak normal karena $2 / 3$ dari 
kasus neuritis optik ialah retrobulbar, sedangkan $1 / 3$ pasien dengan neuritis optik mengalami pembengkakan diskus khususnya pada kasus papilitis. Pada tahap awal papilitis memiliki karakteristik adanya batas diskus yang pucat dan sedikit hiperemis sedangkan pada neuritis retrobulbar mengalami perubahan lanjut yaitu awalnya diskus tampak normal, dan setelah 4-6 minggu dapat dijumpai diskus yang pucat. $^{3}$

\section{SIMPULAN}

Pada kasus neuritis optik didapatkan lebih banyak pada jenis kelamin laki-laki, rentang usia 26-45 tahun, dengan jenis neuritis optik yang tidak diklasifikasi. Kejadian neuritis optik tidak ada hubungannya dengan pekerjaan.

Bagi dokter yang memeriksa perlu menentukan jenis neuritis optik agar dapat memberikan informasi tentang angka kejadian dari setiap jenis neuritis optik. Pasien yang telah didiagnosis neuritis optik perlu diperhatikan pengobatanya karena penurunan penglihatan bisa bersifat permanen dan salah satu komplikasi yang dapat timbul yaitu kerusakan saraf optik.

Bagi Instalasi Rekam Medik RSUP Prof. Dr. R. D. Kandou Manado agar senantiasa meningkatkan kualitas pencatatan baik pada buku registrasi rawat jalan maupun catatan rekam medik.

\section{Konflik Kepentingan}

Penulis menyatakan tidak terdapat konflik kepentingan dalam studi ini.

\section{DAFTAR PUSTAKA}

1. Ilyas S. Ilmu Penyakit Mata (2nd ed). Jakarta: FKUI, 2009; p. 9-10, 180.

2. Hidayat M. Clinical profile of bilateral optic neuritis. Jurnal Kesehatan Andalas. 2018; 7:29-33.

3. Ergene E. Adult optic neuritis. 2019 Jul 01 [ cited 2019 Aug 23 ]. Available from: https://emedicine.medscape.com/article /1217083-overview\#a4

4. Denniston AKO, Murray PI. Oxford Handbook of Ophthalmology (3rd ed). Oxford: Oxford University Press, 2014 p. 660.

5. Siregar NH. Papilitis. USU digital library. 2003:1-6. Available from: http:// repository.usu.ac.id/bitstream/1234567 89/3534/3/pnymata-nurchaliza1.pdf.txt

6. Chan JW. Optic neuritis. Optic Nerve Disorders Diagnosis and Management. New York: Springer, 2010; p. 12.

7. Hartono. Simptomatologi dalam Neurooftalmologi (Cetakan I). Yogyakarta: Pustaka Cendekia Press, 2009; p. 4.

8. Voss E, Raab P, Trebst C, Stangel M. Clinical approach to optic neuritis: pitfalls, red flags and differential diagnosis. Ther Adv Neurol Diso. 2011;2:123-4. 